\title{
$\mathrm{XX}$
}

\section{Ueber einige Probleme der experimentellen Krebsforschung ${ }^{1}$ ).}

\author{
Von \\ Prof. C. 0. Jeilsen (Kopenhagen).
}

Hochangesehene Versammlung! Im Namen des dänischen Cancerkomitees habe ich die Ehre, die eben begründete Internationale Vereinigung: für Krebsforschung zu begrüssen. Die Krebskrankheiten kommen in allen Ländern vor und werden mit vollem Recht iiberall als eine der grössten Plagen der Nenschheit gefürchtet. Jeder Fortschritt in unserer Erkenntnis des Leidens ist deswegen mit lebhaiter Freude, jede Bestrebung zur Förderung unserer Forschung, jede Bestrebung, den Kranken das Leben zu erleichtern, mit Anerkennung zu begruissen. Ich bringe ans Dänemark einen herzlichen Dank an das Deutsche Zentralkomitee für Krebsforschung für seine bahnbrechende Wirksamkeit mit Bezug auf die Organisation der Krebsforschung und Krebsbekämpfung, - einen herzlichen Dank auch an diejenigen Herren, die die Internationale Vereinigung für Krebsforschung. geplant und jetzt trotz aller Schwierigkeiten ins Leben gerufen haben.

Möge die Arbeit, zu welcher so viele Nationen heute ihre Mitwirkung: versprochen haben, von Erfolg gekrönt werden. -

Meine Herren! Es ist mir weiter der ehrenvolle Aultrag erteilt worden, bei dieser Gelegenheit einen Vortrag zu halten. Nur mit grossem Bedenken bin ich der Aufforderung nachgekommen, denn da umfassende Arbeiten anderer Art während der letzten Jahre meine Zeit gänzlich in Beschlag genommen haben, konnte ich mich mit Krebsuntersuchungen nur in geringem Umfange beschäftigen. Es scheint mir indes, dass die Bedeutung der experimentellen Krebsforschung, wie sie sich in den jüngsten Jahren ausgestaltet hat, anch bei einer Gelegenheit wie dieser hervorgehoben werden muss, und ohne mich in die Einzelheiten betreffs der bereits errungenen Resultate zu verlieren, möchte ich gern die wenigen,

1) Vortrag, gehalten in der begründenden Sitzung der Internationalen Vereinigung für Krebsforschung am 23. Mai 1908 in Berlin. 
mir zur Verfïgung stehenden Minuten benutzen, um kurze Bemerkungen iiber mehrere Punkte zu machen und verschiedene Aufgaben der Zukunft auf diesem Gebiete anzudeuten.

Nur wenige Jahre sind rerflossen, seitdem Arbeiten von Loeb, Borrel und mir die Aufmerksamkeit auf die Mäuse- und Rattengeschwälste lenkten als ein Material, das eine experimentelle Geschwulstforschung: ermöglicht, ein Material, das uns befähigt, in bisher unbekannter Weise die biologischen Verhältnisse der Geschwulstzellen, die Bedingungen für das Wachstum und die Metastasierung der Geschwülste im Organismus, die Reaktion des Organismus gegen die Geschwulstzellen usw. zu studieren, ein Material, das sich zu Heilversuchen und zu zahlreichen anderen Versuchen der mannigfachsten Arten eignet. Wie die einfachen bakteriologischen Arbeitsmethoden zur Folge hatten, dass sozusagen jedermann sich die Bakteriologie zu eigen zu machen vermochte, so haben die genannten Arbeiten bewirkt, dass die experimentellen Canceruntersuchungen in zahlreichen Laboratorien in der ganzen. Welt anfgenommen worden sind. Das Misstrauen, das man diesen Untersuchungen anfangs entgegenbrachte, ist jetzt geschwunden, und wenn man auch nicht berechtigt ist, die an den kleineren Tieren gewonnenen Tatsachen ohne weiteres anf die Tumoren des Menschen zu ïbertragen, so ist man jetzt doch wohl darüber einig, dass die durch zahllose Versuche an Mäusen und Ratten gewonnenen Resultate mit Bezug auf Carcinome, Sarkome, Chondrome und andere Geschwülste eine sehr wertvolle Grundlage - eventuell mit unseren grösseren Haustieren als Mittelgliedern - für die Auffassung der Biologie der Menschengeschwïlste werden bilden können, die man ja nur in sehr beschränktem Lmfange zum Gegenstand experimenteller Untersuchungen machen kann.

Was die bereits errmgenen Ergebnisse betriffi, an denen besonders amerikanische, deutsche, englische, französische und norwegische Forscher Anteil haben, werde ich nicht bei der ziemlich umfassenden Kenntnis verweilen, die wir von der Vita propria der Geschwulstzellen und von deren Widerstandstähigkeit gegen äussere schädliche Einwirkungen physischer und chemischer Art erlangt haben; ebensowenig werde ich mich auf die Immunitätsuntersuchungen einlassen, die teils über den Metastasierungsprozess Licht verbreitet haben, teils gewichtige Argumente gegen die Hypothese von der parasitären Herkunft der bösartigen Geschwïlste brachten, und endlich die Hoffinung auf Fortschritte auch auf dem Gebiete der Therapie erregt haben. Einen Augenblick möchte ich dagegen den mehr oder weniger bedeutenden Aenderungen des Baues der Geschwülste widmen, die man recht oft bei fortgesetzten Transplantationen beobachtet hat; sicherlich haben wir hier mit Aenderungen zu tun, die nicht von einem und demselben Gesichtspunkt aus betrachtet werden 
dürfen; zweifelsohne haben wir in einigen Fällen mit einer - dauerhaften oder vorübergehenden - Umbildung zu schaffen, die einer direkten Wirkung der Flüssigkeiten und der Gewebe des neuen Wirtes zu verdanken ist, während wir ebenso sicher in anderen Fällen nur eine Aeusserung der geschwächten Vitalität der Geschwulstzellen erblicken dürfen; wieder in anderen Fällen müssen wir die Umbildung gewiss als das Ergebnis einer Art Reinzüchtung von Zellen verschiedenartiger Eigenschaften auffassen, als eine Auswahl von Zellen, die sich dem Kochschen Plattenkulturverfahren bei Bakterienzüchtung vergleichen lässt; zu dieser Gruppe von Umbildungen bin ich geneigt, diejenige Umbildung aus einem polymorph-zelligen Sarkom in ein Adenom oder wohl vielmehr in ein Endothelioma adenomatosum zu zählen, die Flexner und Joblings Rattengeschwulst durch Transplantationen auf eine Reihe von Ratten hindurch erlitt. Das grösste Interesse unter diesen Umgestaltungen bietet indes die von Ehrlich, Loeb, Bashford u. a. beobachtete Umbildung von Carcinomen in Sarkome bei zunehmender sarkomatöser Umbildung. des Stromas und Verdrängung des Carcinomgewebes dar, denn das rechte Verständnis dieser Umgestaltung wird möglicherweise zngleich den Schlüssel des bisher so dunklen Cancerproblems liefern.

$\mathrm{Zu}$ Heilversuchen geben die Mäuse- und Rattengeschwülste ein gutes Object $a b$, da man die Geschwülste stets in hinlänglicher Anzahl und in geeigneten Altersstufen haben kann; unter den hierher gehörenden Versuchen nenne ich nur die Radiumbehandlung und die Bemühungen, ein anticanceröses Serum mit zytotoxischen Eigenschaften darzustellen. Durch Versuche von Apolant, Salomonsen, Bashford u. a. wurde dargetan, dass eine kurze Radiumbestrahlung imstande ist, Mäusegeschwülste zu schneller Resorption zu bringen; ich kann diese Mitteilungen supplieren, indem ich gefunden habe, dass die Bestrahlung die Vitalität der Zellen schnell und direkt herabsetzt und dieselben leicht abtötet, ein Verhalten, das dem entspricht, was wir über die Wirkungen der Radiumbehandlung auf Protozoen wissen. Die heilenden Wirkungen sind mithin, zum Teil wenigstens, der direkten Wirkung auf die Zellen und nicht der entstandenen Entzündungsreaktion und den erregten Zirkulationsstörungen allein zu verdanken.

Die Möglichkeit, ein heilendes, spezifisches Antikrebsserum darzustellen, habe ich selbst in meiner ersten Mitteilung über den Mäusekrebs in den Vordergrund gestellt, wenn ich mich auch gleich mit Reservation äusserte; es war mir damals unbekannt, dass durch Transplantation entstandene Mäusetumoren oft spontan resorbiert werden, wenn sie eine gewisse Grösse erlangt haben. In verschiedenen Laboraturien hat man ähnliche Versuche angestellt, jedoch mit negativem Ergebnisse. Meine eigenen Resultate können nicht als ïberzeugend bezeichnet werden, und 
ich möchte mich am liebsten damit beruhigen, dass die von mir erzielten vermeintlich spezifischen Serumwirkungen als spontane Heilungen zu betrachten seien; mit Bezug auf mehrere Fälle ist diese Erklärung zweifelsohne die richtige, andere meiner Versuchsresultate, und zwar namentlich meine allerersten, kann ich aber nicht in dieser Weise erklären, dà spontane Resorption so grosser Geschwülste, wie derjenigen, die nach Serumbehandlung schwanden, nie oder doch nur äusserst selten vorkommt. Trotz der vielen negativen Resultate kann ich deshalb noch jetzt nicht als ausgeschlossen betrachten, dass sich ein spezifisches, zytotoxisches Serum gegen Mäusekrebs wird darstellen lassen, und ich möchte gern ein Wörtlein für diese Seite unseres Forschens einlegen, wenn sie auch hier und da jemand, der dieser Aufgabe Zeit und Arbeit geopfert hat, hoffnungslos erscheinen möchte. Man muss ja bedenken, dass auch die Darstellung anderer zytotuxischer Sera auf viele Schwierigkeiten stösst, deren wir noch nicht Meister sind.

Von verschiedenen Seiten, und zwar namentlich von Ehrlich, ist die enorme Proliferationsfähigkeit der Krebszellen als das Zentrale der Malignität des Cancers hervorgehoben worden, und wenigstens zum Teil mit Recht. Ehrlich hat ferner versucht, diese abnorme Proliferationsfähigkeit von der Annahme aus zu erklären, dass die Cancerzellen grössere Affinität zu den Nahrungsstuffen hätten, als die Zellen der normalen Gewebe. Durch diese Annahme gelangen wir direkt zur Frage nach den chemischen Lebenstätigkeiten der Zellen, ein Gebiet, das uns bekanntlich grösstenteils noch ein versiegeltes Buch ist; nur in sehr wenige der hierher gehörenden Probleme hat man bisher einzudringen vermocht, und hinsichtlich der Geschwulstzellen wissen wir ja noch weniger als hinsichtlich der Zellen der normalen Gewebe. Ich wies seinerzeit nach, dass bei Aufbewahrung exzidierten Mäusekrebsgewebes bei Körpertemperatur autoIytische Vorgänge erscheinen, und später hat man auch in menschlichen Krebsgeschwülsten stark wirkende autolytische Enzyme konstatiert. Bei allen von mir untersuchten Mäusecancerstämmen tritt unter den genannten Verhältnissen Autolyse ein; ganz anders verhält sich dagegen das von mir: beschriebene Spindelzellensarkom bei Ratten. Noch nach 48 stündiger Aufbewahrung bei Körpertemperatur haben die Sarkomstückchen keine makroskopischen Aenderungen erlitten, und das histologische Bild ist ebenfalls in allem wesentlichen unverändert, nur die Kerne erweisen sich als ein wenig pyknotisch; dessen ungeachtet gelingt die Transplantation nicht, wèn das Gewebe etwa 20 Stunden in der genannten Wärme gelegen hat, ein Zeugnis, dass die Autolyse wohl kaum der tödliche Faktor bei dem raschen Absterben des Geschwulstgewebes ist, wenn dieses bei Körpertemperatur aufbewahrt wird. Es erleidet indes wohl keinen $Z$ weifel, dass die rollfertig gebildeten antolytischen Fermente imstande sind, auch die 
lebenden Zellen zu beeinflussen. Wir werden deshalb auch durch Injektion eines Extraktes von autolytischem Geschwulstgewebe in den Tumor selbst Zerfallprozesse in diesem hervorrufen können; grösseres Interesse würde es darbieten, wenn man durch Injektion an einer dem Tumor entfernten Stelle infolge der universellen Einwirkung auf das Tier eine Wirkung auf den Tumor elzeugen könnte. Ich habe mehrere derartige Versuche angestellt, indem ich Krebsmäuse mit wiederholten Injektionen autolysierter Tumormasse behandelte. Auffallend häufig erlitten die Geschwülste einen enormen und raschen Zerfall, indem das Wachstum des Gewebes doch an der Peripherie fortdauerte; in einem einzelnen Falle beobachtete ich ausser dem Zerfall ein so umfangreiches Metastasieren nach inneren Organen, wie man ein solches sonst niemalls sieht; wieder in anderen Fällen hörte das Wachstum der Geschwulst auf, oder es traten deutliche, jedoch langsam verlaufende atrophische Zustände ein. Wegen der Geneigtheit des Mäusekrebses zu Zerfallprozessen, wegen der nicht seltenen spontanen Heilung: derselben und wegen des oft sehr verschiedenartigen Verlaufes der Impfgeschwïlste ist es indes an diesem Punkte wie an so vielen anderen sehr schwierig, aus den Versuchen zuverlässige Schlüsse zu ziehen; ich kann mich jedoch des Eindrucks nicht erwehren, dass die Behandlung mit autolysierter Tumormasse etwas störend auf die Ernährung des Geschwulstgewebes und mithin auf die Wachstumsverhältnisse der Geschwulst wirkt. Eine Einwirkung autolysierten Carcinomgewebes auf Rattensarkome wurde dagegen nicht beobachtet. Wenn die vorliegenden Resultate auch zweifelhaft sind, geben sie doch Anregung zur Fortsetzung der Arbeiten mit den autolytischen Prozessen und zur Erforschung der Fermente und der Profermente in den Geschwulstzellen. Inwiefern Arbeiten in dieser Richtung. $\mathrm{zu}$ therapeutischen Ergebnissen führen werden, lässt sich nicht voraussagen, zweifelsohne werden sie aber Aufschlüsse geben, die die eigentümlichen und rätselhaften Verhältnisse der Cancerzellen ein wenig beleuchten können.

Nach diesen Problem, einem der schwierigsten der Krebsforschung, werde ich jetzt ein Problem ungleich gröberer Art erwähnen, das bisher nur: eben berührt worden ist, das in den kommenden Jahreu aber unbedingt durch Versuche in grossem Umfange untersucht werden sollte; ich ziele hiermit auf Haalands Beobachtung hin, dass Mäuse durch Umpflanzung aus Frankfurt a. M. nach Norwegen gegen einen Tumorstamm immun wurden, für den sie früher sehr empfänglich waren, ein Verhalten, das, weun es Bestätigung findet, sich kaum anders demn als Folge der stattgefundenen Aenderung der Ernährungsweise erklären lässt. Ich habe derartige Versuche in Angriff genommen, um zu konstatieren, teils ob eine monatelang durchgeführte einseitige Fütterung und teils ob ein mehrere Generationen hindurch beibehaltener Unterschied in der Fütterung: 
imstande ist, die Empfänglichkeit der Mäuse für einen bekannten Tumorstamm zu ändern. Diese Frage besitzt nicht nur theoretisches Interesse, sondern möglicherweise auch praktische Bedeutung. Mit Recht hat man die durch Transplantationen erregten Geschwülste mit den durch Netastasierung entstandenen verglichen; sellte es sich erweisen, dass man durch eine in wesentlichen Beziehungen geänderte Ernährungsweise die Empfänglichkeit der Mäuse für diese künstlichen Metastasierungen abzuändern vermöchte, so liesse sich die Möglichkeit nicht von vornherein ausschliessen, dass man auch beim Menschen durch stark geänderte Ernährungsverhältnisse in günstiger Weise auf die Metastasierung und namentlich auf die Rezidivierung einen Einfluss ausüben könnte.

Derartige Versuche sind, um zuverlässige Resultate zu liefern, an einer grossen Anzahl von Tieren und an sehr gleichartigem Mäusematerial anzustellen. Dies gilt in noch höherem Masse, wenn wir uns mit Aussicht auf wirkliche Erfolge mit einigen anderen von denjenigen Problemen beschäftigen wollen, die sich jetzt zur experimentellen Untersuchung aufnehmen lassen, was sie meiner Ansicht nach in möglichst grossem Masse verdienen. Ich denke hierbei an die Vererblichkeit oder Nichtvererblichkeit des Mäusekrebses und an die Bedingungen, unter welchen die spontanen Mäuse-und Rattengeschwülste entstehen.

Die Untersuchungen über die Vererblichkeit des Mäusekrebses stossen auf gewisse Schwierigkeiten; in den meisten Fällen entstehen die spontanen Geschwülste zu einem Zeitpunkt, wo die Zeugungsfảhigkeit der Maus aufgehört hat oder nur gering ist; ferner verläuft die Geschwulstbildung gewöhnlich so rasch, dass es der trächtigen Maus nicht rergönnt wird, ihre Jungen zu gebären und grosszusäugen. Auch andere Schwierigkeiten, z. B. Epidemien, welche die mühselig erzielte Brut dahinraffen, können der Durchführung der Versuche in hohem Grade hinderlich sein. Es liegen einzelne Mitteilungen über solche Vererblichkeitsuntersuchungen vor, die ein negatives Resultat ergaben, wie auch über eine einzelne - von Tyzzer ausgeführte - , die andeuten könnte, dass Lungenadenome vererbt werden k.önnen, die mir aber unter Berücksichtigung der Häufigkeit dieser Adenome doch nicht überzeugend scheint. Es findet sich indes eine Reihe von Beobachtungen, dass nahe verwandte Mäuse und Ratten von Geschwülsten angegriffen worden sind, wie sich denn auch bei wenigstens einem grösseren Teile der wohlbekamnten Fälle von Krebsenzootien unter Mäuseund Rattenbeständen die Möglichkeit einer hereditären Uebertragung nicht ausschliessen lässt. So beobachtete ich unter einem englischen Mäusestamm eine Reihe spontaner Geschwülste, während in demselben Zeitraum keine solche unter dänischen Mäusen auftrat, die in denselben Räumen und unter ganz denselben Verhältnisșen gehalten wurden. 
Ich selbst hatte Gelegenheit, zwei Versuchsreihen auszuführen. In der einen gelang es, von einer trächtigen Cancermaus ausgehend, im ganzen etwa $50 \mathrm{zu} \mathrm{4-5}$ Generationen gehörende Mäuse gross zu bringen; keine derselben bekam Tumor. Die andere Reihe bietet dagegen einiges Interesse dar; eine spontane Krebsmaus hinterliess 4 Junge, von denen eins ein enormes intraabdominales Rundzellensarkom bekam; 2 der anderen Jungen - beides Männchen - wurden zur Zucht benutzt und es kamen 400-500 zu 6-7 Generationen gehörende Mäuse zur Beobachtung; leider waren die lokalen Verhältnisse jämmerlich, viele Mäuse starben früh an Epidemien und viele entwischten. Dennoch traten unter diesem Stamm zwei Fälle ${ }^{1}$ ) von gewöhnlichen Krebsgeschwïlsten auf.

Das Problem der Vererblichkeit ist so wichtig, dass es meiner Ansicht nach in möglichst grossem Umfange aufgenommen werden sollte; allerdings sind die Untersuchungen mühevoll, sie lassen sich aber durchführen, wenn von Anfang an ein guter Plan befolgt wird. Dasselbe diurfte auch von Versuchen gelten, die den Nachweis bezwecken, unter welchen Lebensverhältnissen die spontanen Geschwülste bei Mäusen und Ratten entstehen. Derartige Versuche müssen notwendigerweise sehr umfassend sein, wenn sie Auskunft verschaffen sollen. Und nicht nur diese, sondern auch Untersuchungen über die Vererblichkeit und über Aenderungen der Empfänglichkeit lassen sich in dem erforderlichen Umfange wohl nicht leicht von einem einzelnen Forscher oder in einem einzelnen Laboratorium ausfïhren, und ich möchte es für sehr erwünscht halten, dass mehrere Laboratorien ein Zusammenwirken mit Bezug auf diese und ähnliche Untersuchungen vereinbarten, die, um wirklich zuverlässige Aufschlüsse zu geben, nicht Hunderte oder Tausende, sondern Hunderttausende von Versuchstieren erfordern. Möchte unsere neue Internationale Vereinigung für Krebsforschung dazu beitragen, dass die verschiedenen Laboratorien zur Lösung wichtiger Probleme, die umfassende Arbeiten erheischen, zusammentreten, dann werden wir schon aus diesem Grunde allen Anlass haben, die Stiftung der Vereinigung mit Erwartung und Freude zu begrüssen.

1) Später noch einige Fälle. 